\title{
Selective Hydrogenation of Cinnamaldehyde over Pt and Pd Supported on Multiwalled Carbon Nanotubes in a $\mathrm{CO}_{2}$-Expanded Alcoholic Medium
}

Bao-Hui Zhao, ${ }^{\dagger, \ddagger}$ Jian-Gang Chen, ${ }^{\dagger, \ddagger}$ Xuan Liu, ${ }^{\dagger, \ddagger}$ Zhong-Wen Liu, ${ }^{\dagger, \ddagger}$ Zhengping Hao, ${ }^{\dagger, \S}$ Jianliang Xiao, ${ }^{\dagger, \perp}$ and Zhao-Tie Liu* ${ }^{*},+$

${ }^{\dagger}$ Key Laboratory of Applied Surface and Colloid Chemistry, Ministry of Education, Xi'an 710062, China

${ }^{\ddagger}$ School of Chemistry \& Chemical Engineering, Shaanxi Normal University, Xi'an 710062, China

${ }^{\S}$ Research Center for Eco-Environmental Sciences, Chinese Academy of Sciences, Beijing 100085, China

${ }^{\perp}$ Department of Chemistry, University of Liverpool, Liverpool L69 7ZD, U.K.

ABSTRACT: Pt/MWCNT and Pd/MWCNT nanocatalysts were prepared via a liquid reduction method. The selective hydrogenation of cinnamaldehyde (CAL) was investigated over 5.0 wt.\% Pt/MWCNT and 5.0 wt.\% Pd/MWCNT catalysts in a $\mathrm{CO}_{2}$-expanded alcoholic medium at different reaction conditions. The hydrogenation selectivities over these two catalyst types were shown to be entirely different. It was found that the Pt/MWCNT catalysts are highly selective for $\mathrm{C}=\mathrm{O}$ bonds, giving the unsaturated alcohol a selectivity for cinnamyl alcohol (COL) of $97.3 \%$ and a conversion rate for cinnamaldehyde of $99.3 \%$. Conversely, the $\mathrm{Pd} / \mathrm{MWCNT}$ catalyst is highly selective for $\mathrm{C}=\mathrm{C}$ bonds, producing a saturated aldehyde with a selectivity for hydrocinnamaldehyde (HCAL) of $91.3 \%$ and a conversion rate for cinnamaldehyde of $98.6 \%$. The small diameter of the Pt or Pd granules over the multiwalled carbon nanotubes (MWCNTs) leads to a high catalyst activity, and an increase of $\mathrm{CO}_{2}$ pressure results in a better hydrogenation performance for $\mathrm{C}=\mathrm{O}$ bonds than that for $\mathrm{C}=\mathrm{C}$ bonds.

\section{INTRODUCTION}

$\alpha, \beta$-Unsaturated aldehydes are important chemical raw materials and intermediates in industrial production, and the selective reduction of these compounds is an important topic in the field of catalytic research. As a representative $\alpha, \beta$ unsaturated aldehyde, cinnamaldehyde (CAL) is particularly important because its two partial hydrogenation products, cinnamyl alcohol (COL) and hydrocinnamaldehyde (HCAL), are important intermediates for the syntheses of many fine chemicals, particularly flavors, perfumes, and pharmaceuticals. $^{1-4}$ The selective hydrogenation of CAL is a challenging reaction as it contains conjugated $\mathrm{C}=\mathrm{C}$ and $\mathrm{C}=\mathrm{O}$ bonds, and reduction of the $\mathrm{C}=\mathrm{C}$ bond is thermodynamically more favorable. Selective hydrogenation can be achieved over some noble metal-supported catalysts that show highly selective activity. ${ }^{5-8}$ For instance, platinum and palladium are the most active metals that can be used in CAL selective hydrogenation reactions, with platinum reducing $\mathrm{C}=\mathrm{O}$ bonds and palladium reducing $\mathrm{C}=\mathrm{C}$ bonds. In addition to the noble metals, the catalyst support can also remarkably influence the catalytic activity and product distribution of these reactions. ${ }^{9-11}$ Since multiwalled carbon nanotubes (MWCNTs) were first discovered by Iijima in 1991, ${ }^{12}$ they have received increasing scientific and industrial interest due to their exceptional properties, such as a large specific surface area, a special aperture structure, a high mechanical stability, a high length-to-diameter aspect ratio, and electrical properties. ${ }^{13,14}$ In recent years, numerous reports have shown that carbon nanotube-supported noble metal catalysts are the most widely used catalytic supports for hydrogenation reactions. ${ }^{15-17}$ For different MWCNT supports, the curvatures of the outmost tubes have determined the different selectivities of the Pt/MWCNT catalysts during the hydrogenation of CAL. ${ }^{18}$

In recent years, $\mathrm{CO}_{2}$-expanded liquids (CXLs) have achieved significant attention as a novel chemical reaction medium in a variety of applications. CXL is generally a mixed solvent system composed of $\mathrm{CO}_{2}$ gas dissolved in an organic solvent. ${ }^{19}$ Because of the environmentally benign advantages of $\mathrm{CO}_{2}$ and because it is inexpensive, safe, and nontoxic, CXLs combine the beneficial properties of $\mathrm{CO}_{2}$ and traditional organic solvents. Hydrogenation reactions in liquids are limited by the rate of diffusion of hydrogen from the gas through the liquid phase, and this biphasic system may be reduced to a single phase by adding CXLs. CXLs not only enhance the miscibility of the liquid reactant and hydrogen gas, but the liquid also reduces the solution viscosity and increases the hydrogen diffusion rate to remove mass transfer resistance. ${ }^{20-22}$ Therefore, CXLs are particularly useful as an environmentally benign medium for selective catalytic hydrogenation reactions.

In this paper, we have investigated the catalytic properties of Pt and Pd nanoparticles supported on multiwalled carbon nanotubes (MWCNTs) for CAL hydrogenation in CXLs. The influences of several operating parameters, including phase behavior, reaction time, $\mathrm{H}_{2}$ pressure, $\mathrm{CO}_{2}$ pressure, temperature, solvent, and catalyst stability, have been investigated.

Received: June 14, 2012

Revised: August 3, 2012

Accepted: August 9, 2012

Published: August 9, 2012 

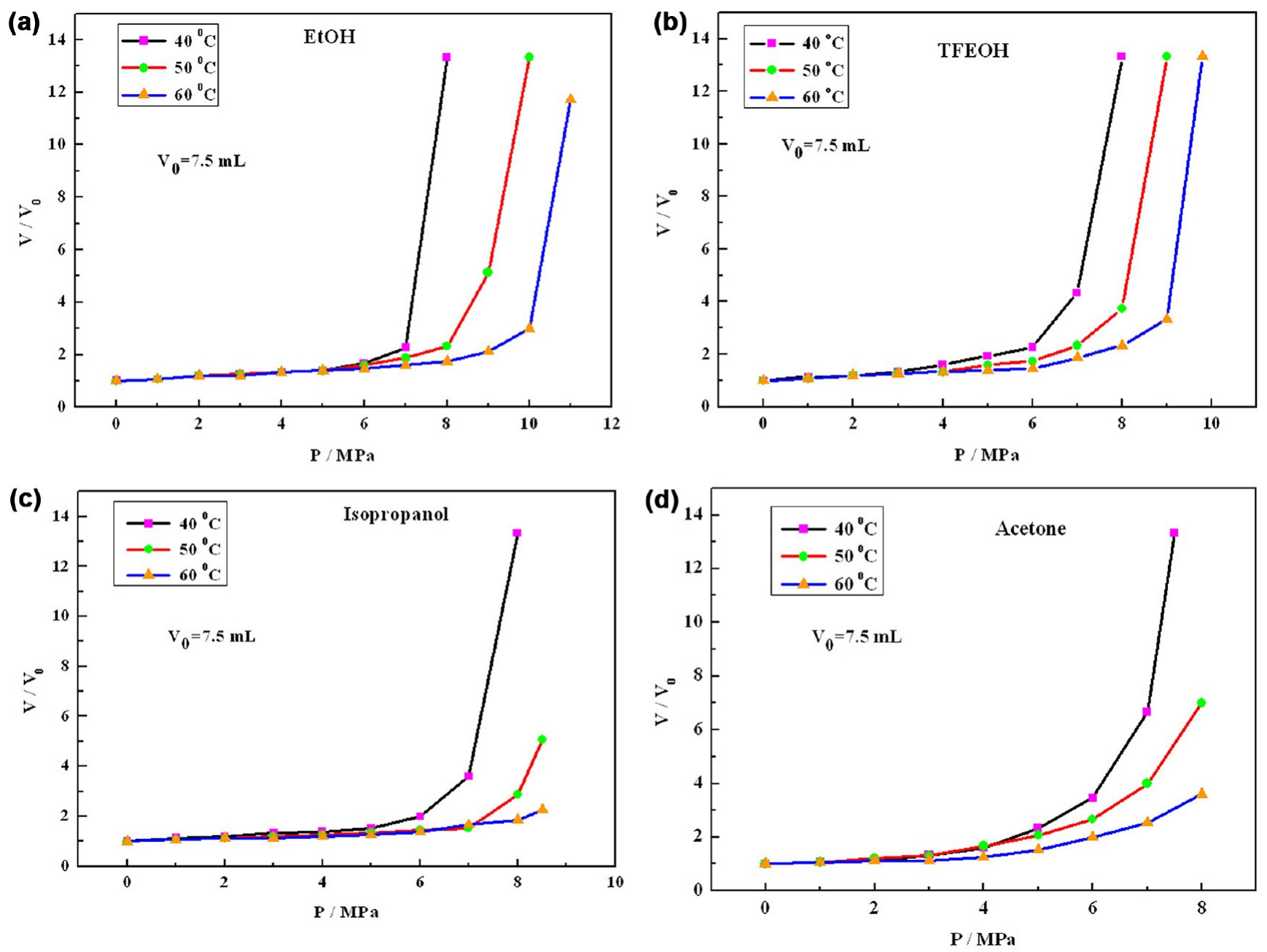

Figure 1. Volume expansion ratios of EtOH, TFEOH, isopropanol, and acetone at different temperatures.

\section{EXPERIMENTAL SECTION}

Materials. MWCNTs were obtained from Chengdu Organic Chemicals Co., Ltd. (Chinese Academy of Sciences). Chemicals such as $\mathrm{CAL}, \mathrm{H}_{2} \mathrm{PtCl}_{6} \cdot 6 \mathrm{H}_{2} \mathrm{O}, \mathrm{PdCl}_{2}$, ethanol $(\mathrm{EtOH})$, trifluoroethanol (TFEOH), isopropanol, acetone, and ethylene glycol were of analytical grade and were used without further purification. The purities of the hydrogen and carbon dioxide gases were $99.9 \%$.

Catalyst Preparation. The carbon nanotubes were stirred in a mixture of concentrated $\mathrm{HNO}_{3}$ and $\mathrm{H}_{2} \mathrm{SO}_{4}$ at $110{ }^{\circ} \mathrm{C}$ for 3 h. After pretreatment, the supports were repeatedly washed with deionized water and filtered. The supports were then dried at $80{ }^{\circ} \mathrm{C}$ and crushed to a powder for storage.

The 5 wt.\% Pt/MWCNT and 5 wt.\% Pd/MWCNT catalysts were prepared by a liquid reduction process. MWCNTs $(0.15$ $\mathrm{g})$ and sodium laurylsulfonate $(0.76 \mathrm{~g})$ were added to $30 \mathrm{~mL}$ of ethylene glycol in a $250-\mathrm{mL}$ flask. To obtain a homogeneous solution mixture, the mixture was stirred at room temperature for $30 \mathrm{~min}$ and then dispersed ultrasonically for $60 \mathrm{~min}$. The solution mixture was heated to $140{ }^{\circ} \mathrm{C}$ in an oil bath before 10 $\mathrm{mL}$ of a solution containing $\mathrm{H}_{2} \mathrm{PtCl}_{6}$ (or $\mathrm{PdCl}_{3}$ ) and ethylene glycol was slowly dropped into the flask. The mixed solution was refluxed at $140^{\circ} \mathrm{C}$ for $3 \mathrm{~h}$. The resulting solid was filtered, washed, and dried at $80{ }^{\circ} \mathrm{C}$ overnight. The Pt/MWCNT and $\mathrm{Pd} / \mathrm{MWCNT}$ catalysts were finally crushed to a powder to use for hydrogenation.
Catalyst Characterization Techniques. High-resolution transmission electron microscopy (HRTEM) was performed to study the catalyst microstructure on a JEM-2100 transmission electron microscope working at a $200 \mathrm{kV}$ accelerating voltage. The catalyst samples were ultrasonically dispersed in ethanol and added onto a porous carbon-coated copper grid. The metal particle distribution on the support surface was obtained by TEM. The X-ray diffraction (XRD) was conducted on a Rigaku $\mathrm{D} / \mathrm{max}-3 \mathrm{c}$ apparatus with $\mathrm{Cu} \mathrm{K} \alpha$ radiation $(\lambda=0.154 \mathrm{~nm})$ from 10 to $80{ }^{\circ} \mathrm{C}(2 \theta)$ operating at $40 \mathrm{kV}$ and $100 \mathrm{~mA}$. The $\mathrm{BET}$ specific surface area and porosity based on the $\mathrm{BJH}$ calculation of the desorption branches were measured on a BEL SORP-max (BEL JAPAN, INC.) using $\mathrm{N}_{2}$ as an absorbent at the liquid nitrogen temperature $\left(-196{ }^{\circ} \mathrm{C}\right)$. Before measurement, the catalyst sample was completely degassed at $100{ }^{\circ} \mathrm{C}$ for $2 \mathrm{~h}$ and then at $350{ }^{\circ} \mathrm{C}$ for $5 \mathrm{~h}$.

Phase Behavior Studies. A high-pressure view cell with an internal volume of $100 \mathrm{~mL}$ and equipped with a quartz window $^{23}$ was used to determine the existing phases and the volume of organic solvents in $\mathrm{CO}_{2}$ at different pressures. A certain amount of organic solvent was added into the view cell and heated in a water bath at different temperatures $(40,50,60$, $\left.70{ }^{\circ} \mathrm{C}\right) . \mathrm{CO}_{2}$ was then introduced into the view cell. The $\mathrm{CO}_{2}$ pressure was slowly increased while stirring. After reaching the desired pressure, the stirring was stopped for a few minutes, and the organic solvent volume was recorded. Finally, the 

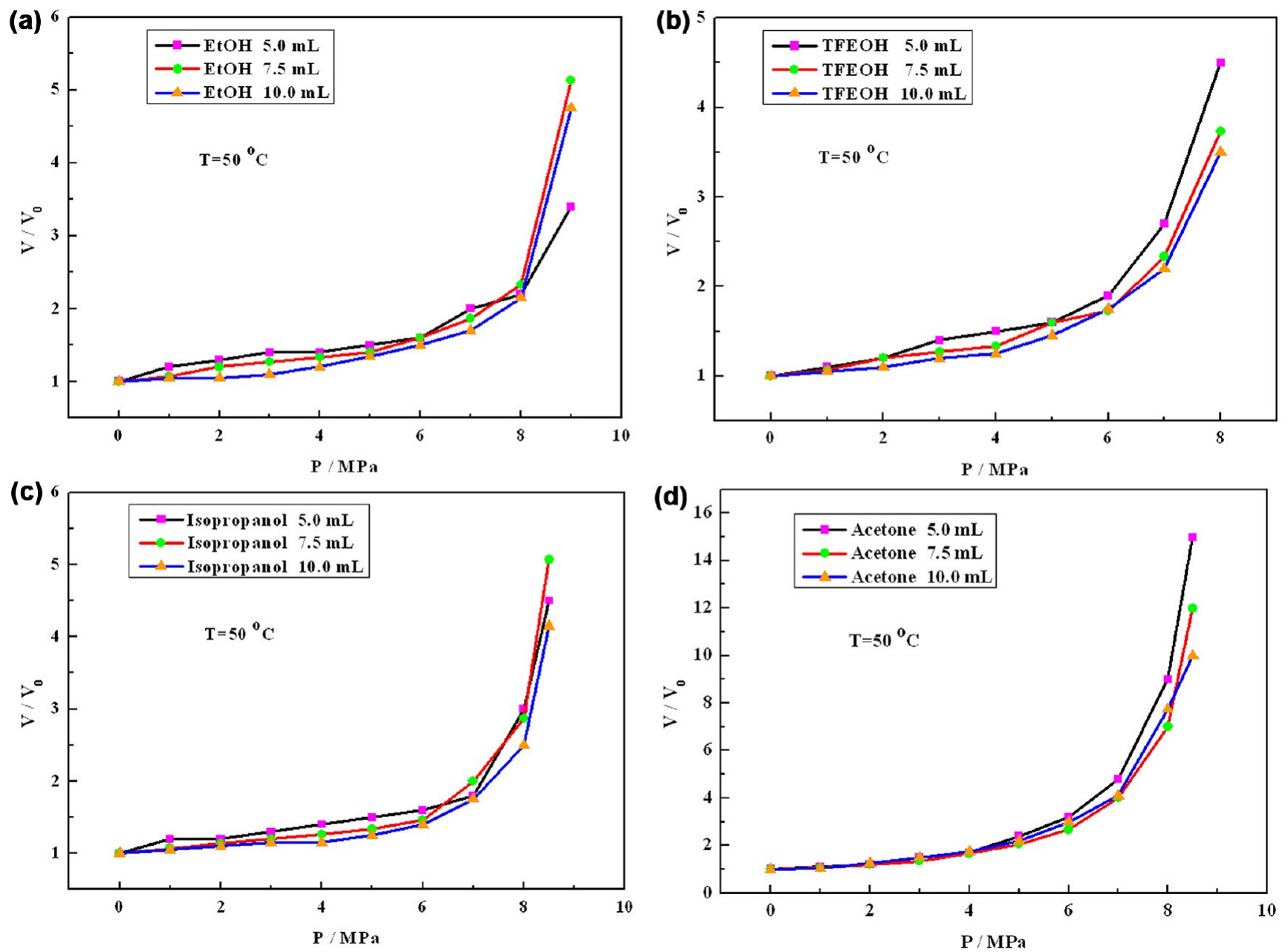

Figure 2. Volume expansion ratios of EtOH, TFEOH, isopropanol, and acetone at different initial volumes.

gaseous and liquid phases of the system were converted to a single phase by increasing $\mathrm{CO}_{2}$ pressure. The interactions between the $\mathrm{CO}_{2}$ molecules and the $\mathrm{C}=\mathrm{O}(\mathrm{C}=\mathrm{C})$ bonds in CAL were measured with an in situ high-pressure FTIR spectrometer (PerkinElmer Spectrum 400) at $60{ }^{\circ} \mathrm{C}^{24}$

Catalyst Activity. The catalytic hydrogenation of CAL was carried out in a high-pressure, stainless steel batch reactor $(100$ $\mathrm{mL}){ }^{22}$ For each experiment, $2 \mathrm{~mL}$ of CAL, $6 \mathrm{~mL}$ of trifluoroethanol, and $0.06 \mathrm{~g}$ of catalyst were added into the reactor, and the reactor was then sealed, flushed with $0.5 \mathrm{MPa}$ $\mathrm{CO}_{2}$ three times and heated to the desired temperature. Hydrogen gas was first loaded into the reactor at a fixed pressure, and $\mathrm{CO}_{2}$ was added into the reactor to the desired total pressure with a high-pressure liquid pump. The reaction was stirred with a magnetic stirrer. After the reaction reached completion, the reactor was cooled to a room temperature in ice-cold water and slowly depressurized to atmospheric pressure. The liquid product was separated from the catalyst by filtration. The liquid mixture was analyzed by gas chromatography equipped with an FID detector and an HP-5 capillary column $(30 \mathrm{~m} \times 0.32 \mathrm{~mm} \times 1.00 \mathrm{~m})$. For recycling experiments, the catalyst was separated after the reaction and ultrasonically redispersed in ethanol for $15 \mathrm{~min}$.

\section{RESULTS AND DISCUSSION}

Selecting of Cosolvent. Figure 1 shows the volume expansion ratios of $\mathrm{EtOH}, \mathrm{TFEOH}$, isopropanol, and acetone

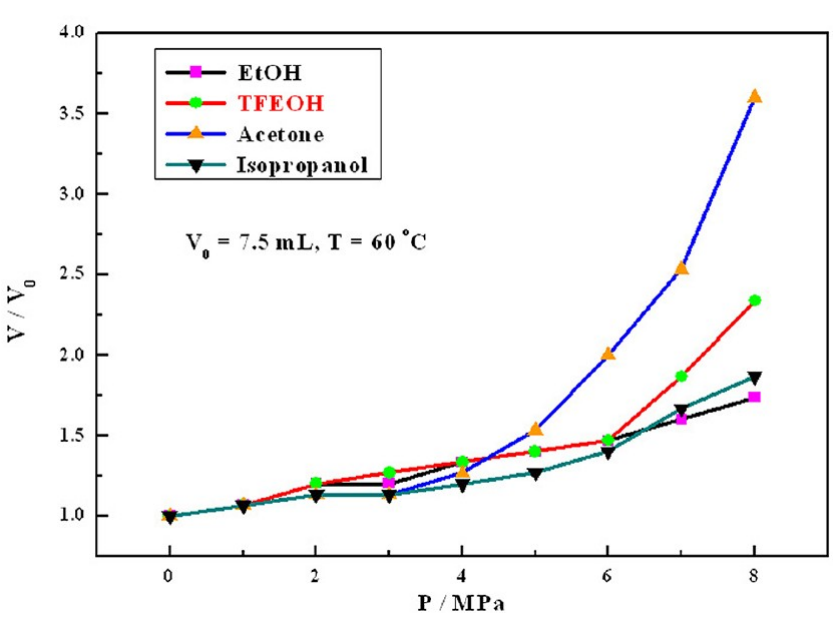

Figure 3. Volume expansion ratios of different polar organic solvents.

at different temperatures in $\mathrm{CO}_{2}$. The expansion performance of the four organic solvents in $\mathrm{CO}_{2}$ decreased with the increase of temperature. Figure 2 shows the volume expansion ratios of $\mathrm{EtOH}, \mathrm{TFEOH}$, isopropanol, and acetone at different initial volumes in $\mathrm{CO}_{2}$. The initial volume of the solvents was not a key factor in their expansion performance at a constant temperature. Figure 3 shows the expansion performance of EtOH, TFEOH, isopropanol, and acetone in $\mathrm{CO}_{2}$ at a constant 


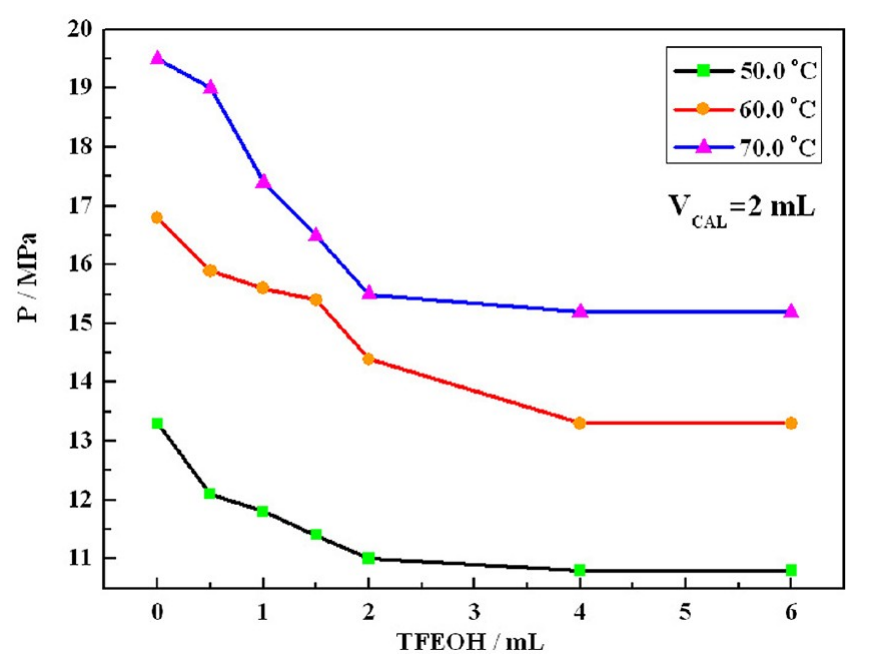

Figure 4. Phase behavior of $\mathrm{CAL}+\mathrm{TFEOH}+\mathrm{CO}_{2}$.

Table 1. Pore Properties and Surface Areas of the Untreated MWCNT, Acid-Treated MWCNT, 5.0 wt.\% Pt/MWCNT, and 5.0 wt.\% Pd/MWCNT Catalysts

\begin{tabular}{cccc} 
catalyst & $\begin{array}{c}\text { BET surface area } \\
\left(\mathrm{m}^{2} \cdot \mathrm{g}^{-1}\right)\end{array}$ & $\begin{array}{c}\text { mesopore volume } \\
\left(\mathrm{mL} \cdot \mathrm{g}^{-1}\right)\end{array}$ & $\begin{array}{c}\text { average pore } \\
\text { diameter }(\mathrm{nm})\end{array}$ \\
$\begin{array}{c}\text { untreated } \\
\text { MWCNT }\end{array}$ & 163 & 0.63 & 26.67 \\
$\begin{array}{c}\text { acid-treated } \\
\text { MWCNT }\end{array}$ & 190 & 0.95 & 19.89 \\
$\begin{array}{c}\text { 5.0 wt.\% Pt/ } \\
\text { MWCNT }\end{array}$ & 182 & 1.11 & 24.25 \\
$\begin{array}{c}\text { 5.0 wt.\% Pd/ } \\
\text { MWCNT }\end{array}$ & 177 & 1.12 & 24.96 \\
\hline
\end{tabular}

temperature and initial volume. It can be observed that an increase in solvent polarity correlates with a weaker expansion performance in $\mathrm{CO}_{2}$. The order of the volume expansion ratios of the solvents is as follows: acetone $>\mathrm{TFEOH}>$ isopropanol $>$ EtOH. Considering that acetone contains a $\mathrm{C}=\mathrm{O}$ bond that may interfere with the CAL selective hydrogenation, TFEOH was used as a cosolvent in the subsequent studies.

Expansion Performance Studies of CAL, TFEOH, and $\mathrm{CO}_{2}$. Figure 4 shows the $\mathrm{CO}_{2}$ pressure changes when the gaseous phase and liquid phase were converted into a single phase with the increase of TFEOH. Low temperatures were beneficial for the volume expansion of CAL and TFEOH in $\mathrm{CO}_{2}$ under the same conditions. The $\mathrm{CO}_{2}$ pressure was the lowest in the homogeneous system when the volume ratio of CAL to TFEOH was equal to or less than 0.5 .

Support and Catalyst Characterization. The surface characteristics (BET surface area, mesopore volume, and average pore diameter) of the MWCNT, $5.0 \mathrm{wt} . \% \mathrm{Pt} /$ MWCNT, and 5.0 wt.\% Pd/MWCNT catalysts are listed in Table 1. The BET surface area and mesopore volume of the MWCNTs treated using a concentrated acid increased compared to the untreated MWCNTs, but the average pore diameter decreased. The surface of the MWCNT catalysts was oxidized and corroded, their average length was shortened, and some carbon particles, amorphous carbon, and metal impurities were removed by the concentrated acid solution. ${ }^{25,26}$ The mesopore volumes of the MWCNT catalyst accounted for the majority of their total volume, and the micropore volumes were negligible for all of the samples as reported in our previous paper. ${ }^{18}$ The mesopore volume and average pore diameter
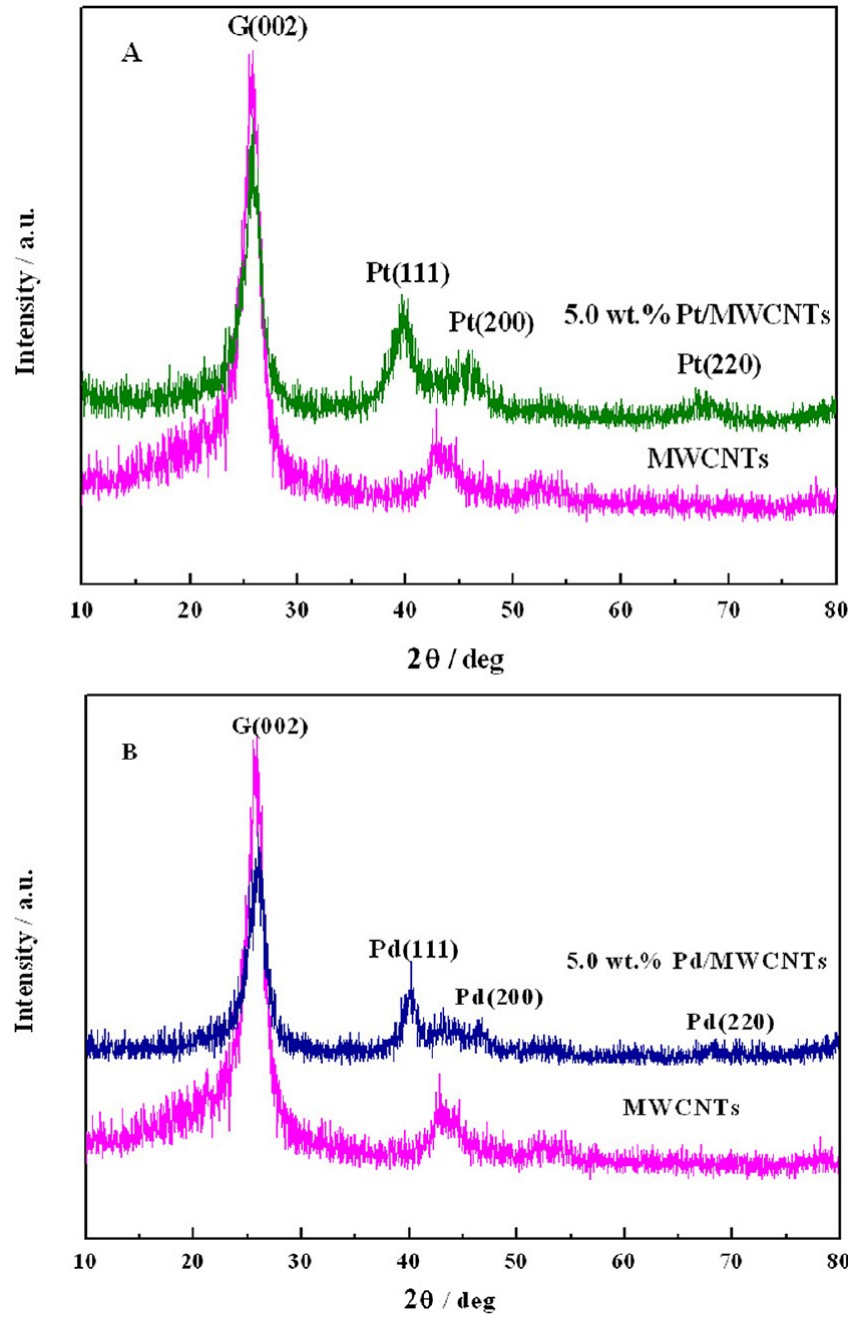

Figure 5. XRD patterns of the MWCNT, Pt/MWCNT (A), and Pd/ MWCNT (B) catalysts.

increased after the acid-treated MWCNTs supported Pt and Pd metals (Table 1). Although both the MWCNTs and the catalysts showed very similar patterns of $\mathrm{PSD},{ }^{18}$ the peaks at smaller pore sizes were obviously intensified for the catalysts. However, the maximum $\mathrm{d} V / \mathrm{d} p$ values of the broad peaks with larger pore diameters were quite similar for the individual MWCNT and the catalyst, indicating that the spaces of the agglomerated MWCNTs are not apparently modified after acidic treatment and loading of $5.0 \mathrm{wt} . \% \mathrm{Pt}$.

Figure 5 shows the XRD patterns of the MWCNT, Pt/ MWCNT (A), and Pd/MWCNT (B) catalysts. The strong diffraction peaks (002) of the hexagonal graphite at a $2 \theta$ angle of $25.8^{\circ}$ indicate that the graphite structure of the MWCNT supports was not destroyed after concentrated acid treatment and Pt or Pd deposition. The characteristic (111), (200), and (220) diffraction peaks of $\mathrm{Pt}$ and $\mathrm{Pd}$ are clearly observed.

Figure 6 shows TEM images of the Pt/MWCNT (a, b, c) and Pd/MWCNT (d, e, f) catalysts. The Pt $(a, b, c)$ and Pd (d, $e, f)$ nanoparticles uniformly dispersed on the outside surface of the MWCNTs. By measuring $1000 \mathrm{Pt}$ and Pd nanoparticles each, the average crystal sizes of metallic $\mathrm{Pt}$ and $\mathrm{Pd}$ in the catalysts were determined to be 2.87 and $3.49 \mathrm{~nm}$, respectively.

Selective Hydrogenation of CAL over 5.0 wt.\% Pt/ MWCNT Catalyst. Effect of Reaction Time. Under the studied reaction conditions, the selective hydrogenation of CAL may 


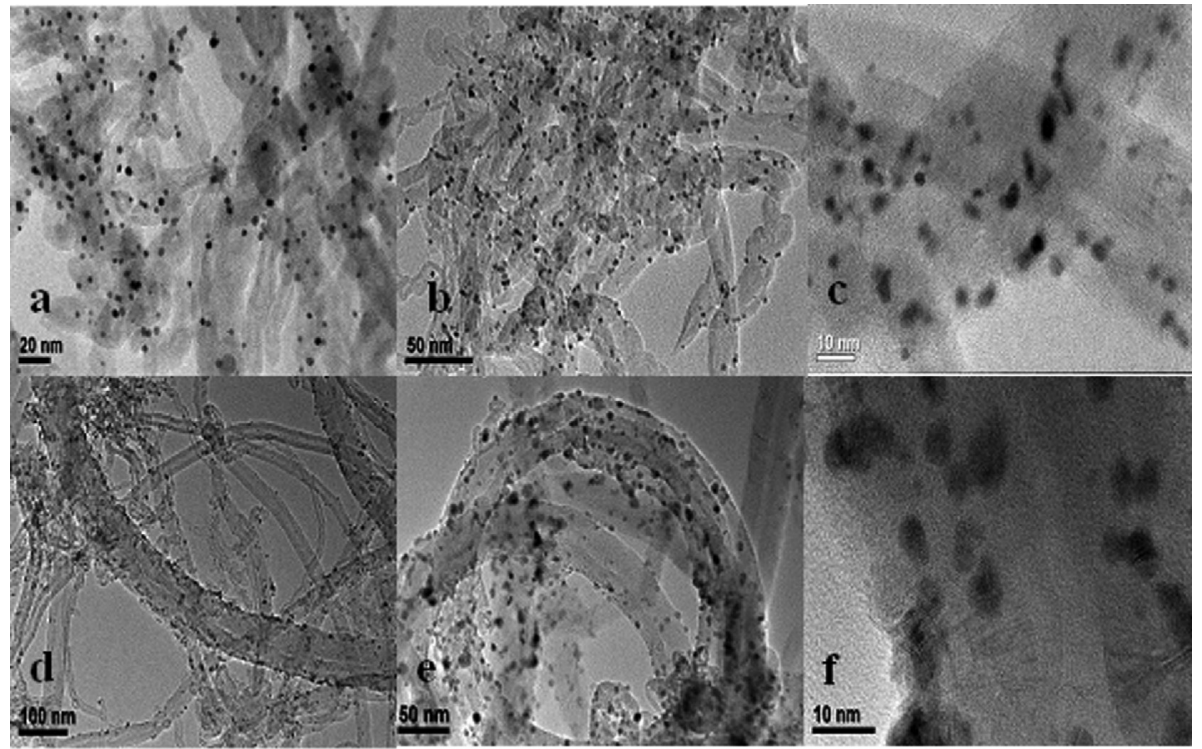

Figure 6. TEM images of the Pt/MWCNT (a, b, c) and Pd/MWCNT (d, e, f) catalysts.

Scheme 1. Reaction Pathways for the Hydrogenation of CAL
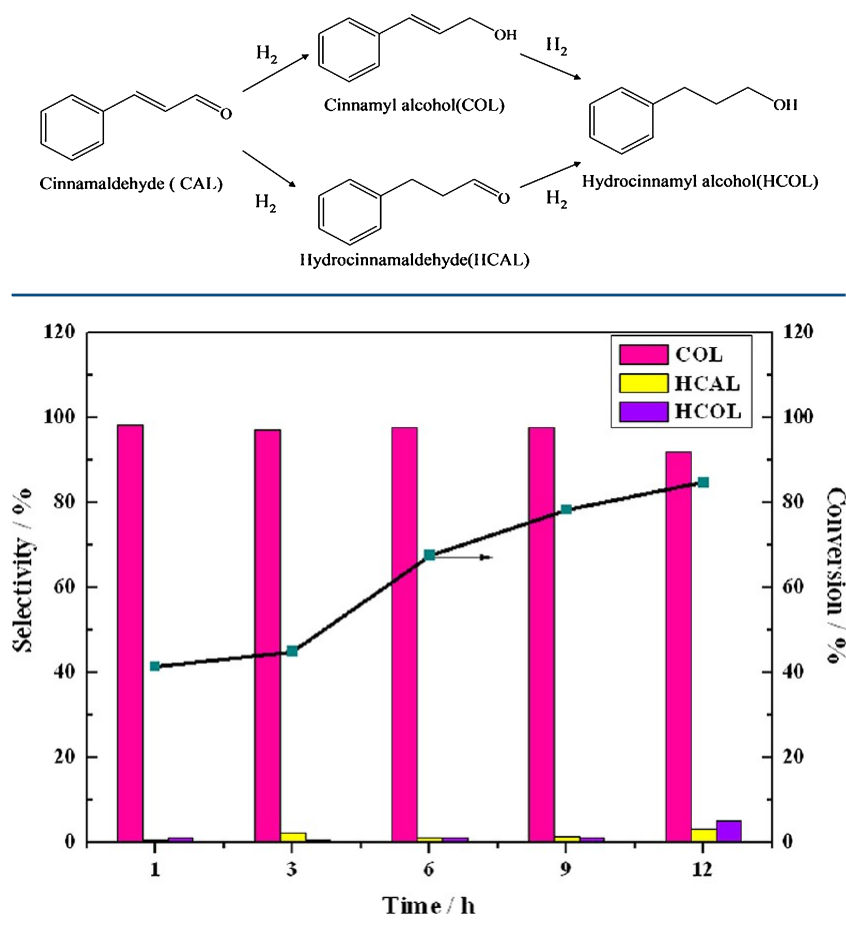

Figure 7. Effect of reaction time on the catalytic performance of the $\mathrm{Pt} / \mathrm{MWCNT}$ catalyst (reaction conditions: $0.06 \mathrm{~g}$ of catalyst, $2 \mathrm{~mL}$ of $\mathrm{CAL}, 6 \mathrm{~mL}$ of TFEOH, $4 \mathrm{MPa} \mathrm{H}_{2}, 14.8 \mathrm{MPa} \mathrm{CO}_{2}, 60^{\circ} \mathrm{C}$ ).

produce cinnamyl alcohol (COL), hydrocinnamaldehyde (HCAL), and hydrocinnamyl alcohol (HCOL) (Scheme 1). Figure 7 shows the effect of reaction time on the product distribution at a constant temperature of $60{ }^{\circ} \mathrm{C}$ over the $\mathrm{Pt} /$ MWCNT catalyst. As the reaction time increased from 1 to $9 \mathrm{~h}$, the CAL conversion amount increased from 41 to $85 \%$, and the selectivity for COL remained at $97 \%$. When the reaction time increased from 9 to $12 \mathrm{~h}$, the COL yield slightly increased from 77 to $78 \%$, but the selectivity for COL decreased to $92 \%$.

Effect of $\mathrm{CO}_{2}$ Pressure. Figure 8 shows the effect of $\mathrm{CO}_{2}$ pressure on the product distribution over $\mathrm{a}_{2}$ pressure range

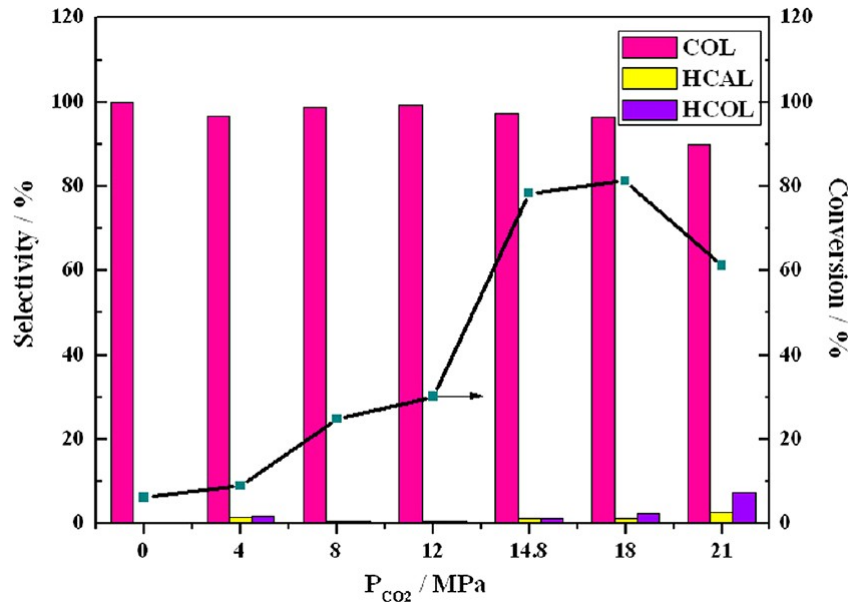

Figure 8. Effect of $\mathrm{CO}_{2}$ pressure on the catalytic performance of the $\mathrm{Pt} / \mathrm{MWCNT}$ catalyst (reaction conditions: $0.06 \mathrm{~g}$ of catalyst, $2 \mathrm{~mL}$ of $\mathrm{CAL}, 6 \mathrm{~mL}$ of TFEOH, $4 \mathrm{MPa} \mathrm{H}_{2}, 60^{\circ} \mathrm{C}, 9 \mathrm{~h}$ ).

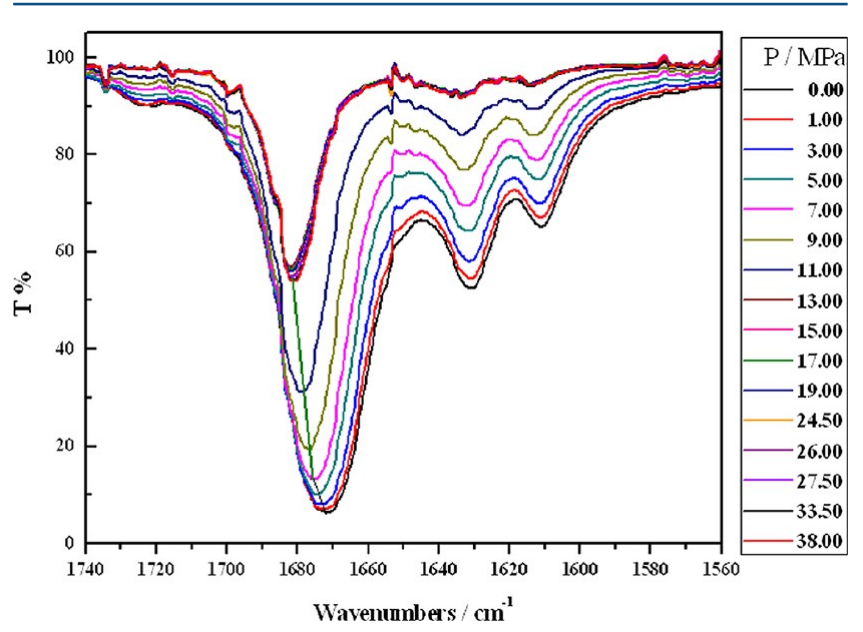

Figure 9. In situ FT-IR spectra of the $\mathrm{CAL}+\mathrm{CO}_{2}$ system with increasing $\mathrm{CO}_{2}$ pressure at $60.0^{\circ} \mathrm{C}$. 


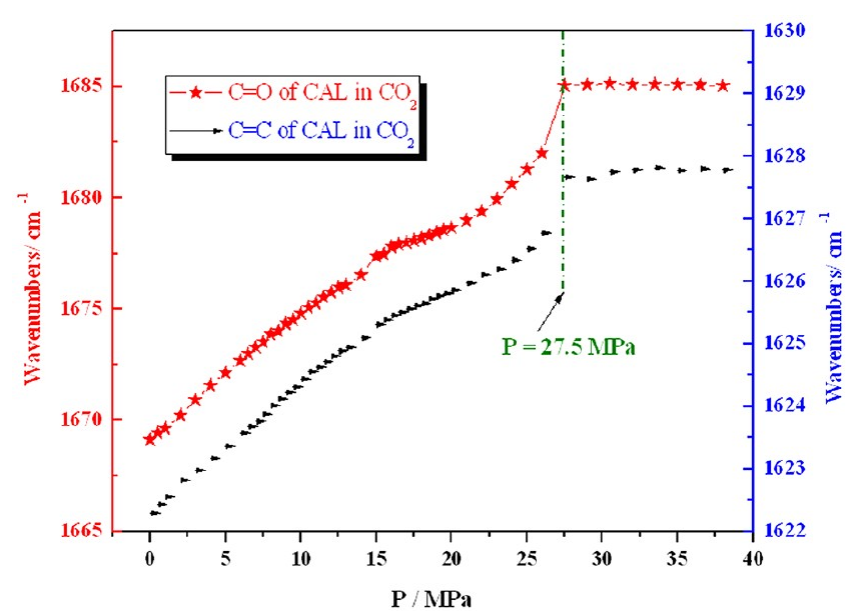

Figure 10. Vibration absorption evolution of $\mathrm{C}=\mathrm{O}$ and $\mathrm{C}=\mathrm{C}$ bonds in $\mathrm{CAL}$ of the $\mathrm{CAL}+\mathrm{CO}_{2}$ system at $60.0^{\circ} \mathrm{C}$ (reaction conditions: 15 $\mathrm{mL}$ of $\left.\mathrm{CAL}, 60^{\circ} \mathrm{C}\right)$.

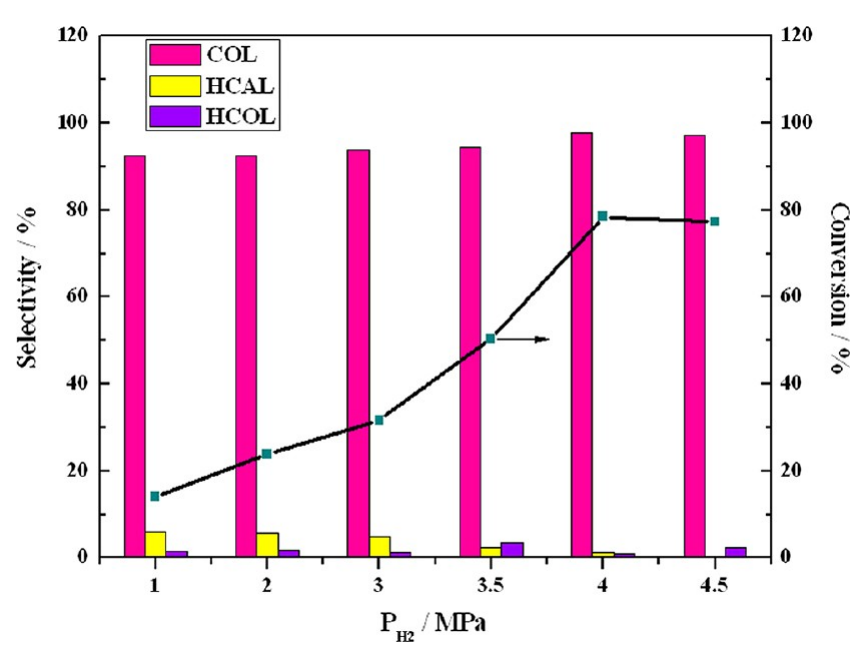

Figure 11. Effect of $\mathrm{H}_{2}$ pressure on the catalytic performance of the Pt/MWCNT catalyst (reaction conditions: $0.06 \mathrm{~g}$ of catalyst, $2 \mathrm{~mL}$ of $\mathrm{CAL}, 6 \mathrm{~mL}$ of TFEOH, $14.8 \mathrm{MPa} \mathrm{CO}_{2}, 60^{\circ} \mathrm{C}, 9 \mathrm{~h}$ ).

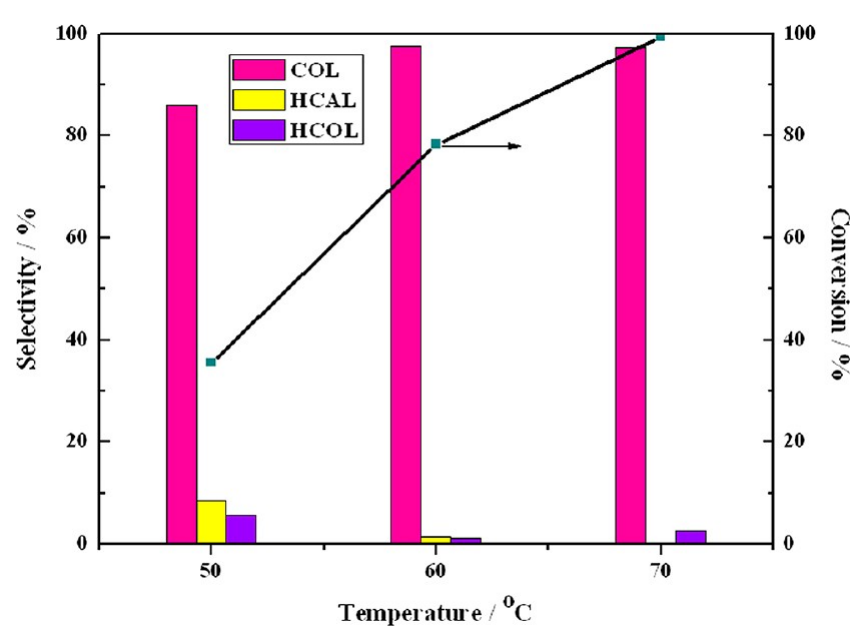

Figure 12. Effect of temperature on the catalytic performance of the $\mathrm{Pt} / \mathrm{MWCNT}$ catalyst (reaction conditions: $0.06 \mathrm{~g}$ of catalyst, $2 \mathrm{~mL}$ of CAL, $6 \mathrm{~mL}$ of TFEOH, 14.8 $\mathrm{MPa} \mathrm{CO}_{2}, 4 \mathrm{MPa} \mathrm{H}_{2}, 9 \mathrm{~h}$ ).

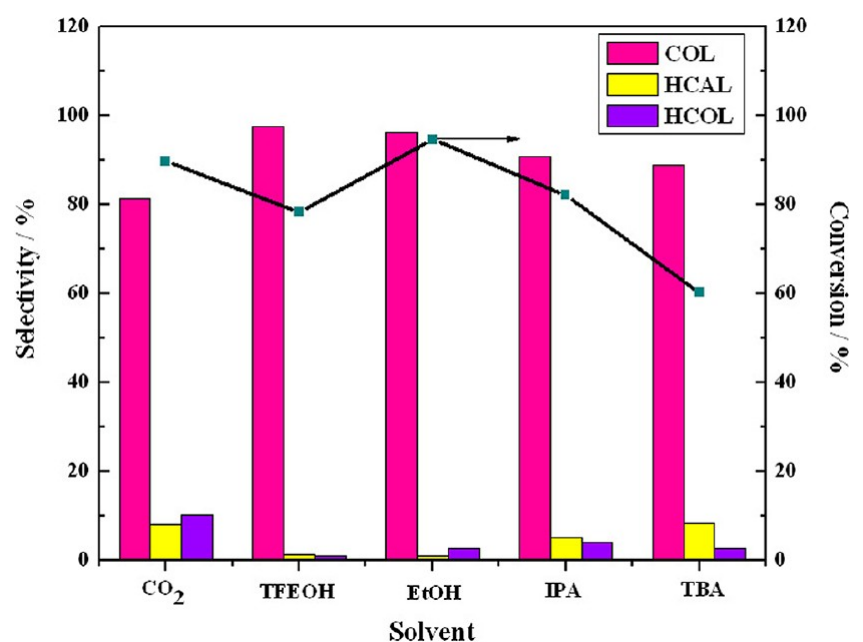

Figure 13. Effect of different cosolvents on the catalytic performance of the Pt/MWCNT catalyst (reaction conditions: $0.06 \mathrm{~g}$ of catalyst, 2 $\mathrm{mL}$ of $\mathrm{CAL}, 4 \mathrm{MPa} \mathrm{H}_{2}, 14.8 \mathrm{MPa} \mathrm{CO}_{2}, 60^{\circ} \mathrm{C}, 9 \mathrm{~h}$ ).

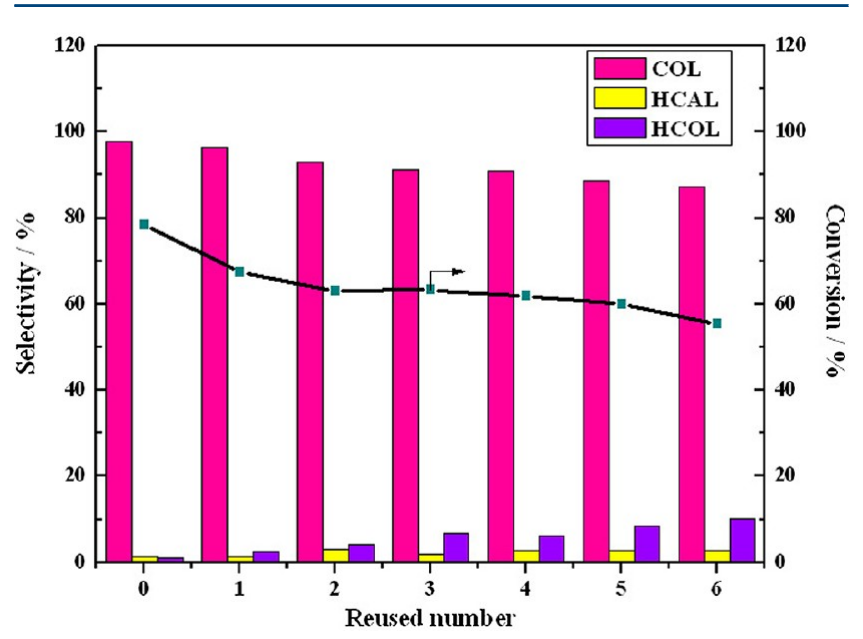

Figure 14. Stability of the $\mathrm{Pt} / \mathrm{MWCNT}$ catalyst (reaction conditions: $0.06 \mathrm{~g}$ of catalyst, $2 \mathrm{~mL}$ of $\mathrm{CAL}, 4 \mathrm{MPa} \mathrm{H}_{2}, 14.8 \mathrm{MPa} \mathrm{CO}_{2}, 60{ }^{\circ} \mathrm{C}, 9$ h).

from 0 to $21 \mathrm{MPa}$ for the selective hydrogenation of CAL over the $\mathrm{Pt} / \mathrm{MWCNT}$ catalyst. The CAL conversion percentage increased gradually with the increase of $\mathrm{CO}_{2}$ pressure, and the selectivity for COL remained above $96 \%$. The results can be classified as three sections for $\mathrm{CO}_{2}$ pressure between 0 and 21 $\mathrm{MPa}$. (1) Below the critical state $(0-4 \mathrm{MPa})$, the system contains both gaseous and liquid phases, and the hydrogenation reaction is limited by the diffusion rate of hydrogen from the gas to the liquid phase, so the CAL conversion is low. As expected, the conversion percentage did not increase much with increasing $\mathrm{CO}_{2}$ pressure (2). In the supercritical state (8$12 \mathrm{MPa})$, supercritical carbon dioxide $\left(\mathrm{scCO}_{2}\right)$ has unique properties compared to conventional organic solvents, such as low viscosity, high diffusivity, and high miscibility with gases, such as $\mathrm{H}_{2}$. While expanding the organic solvent, $\mathrm{CO}_{2}$ can carry $\mathrm{H}_{2}$ into the solvent and improve the reaction rate. Therefore, the CAL conversion percentage increased significantly with increasing $\mathrm{CO}_{2}$ pressure. (3) In the single phase state (above 14.8 $\mathrm{MPa}$ ), the gaseous and liquid phases converge to a single phase in the reaction system. With only one phase, mass transfer resistance does not exist, and the contact surfaces of the 


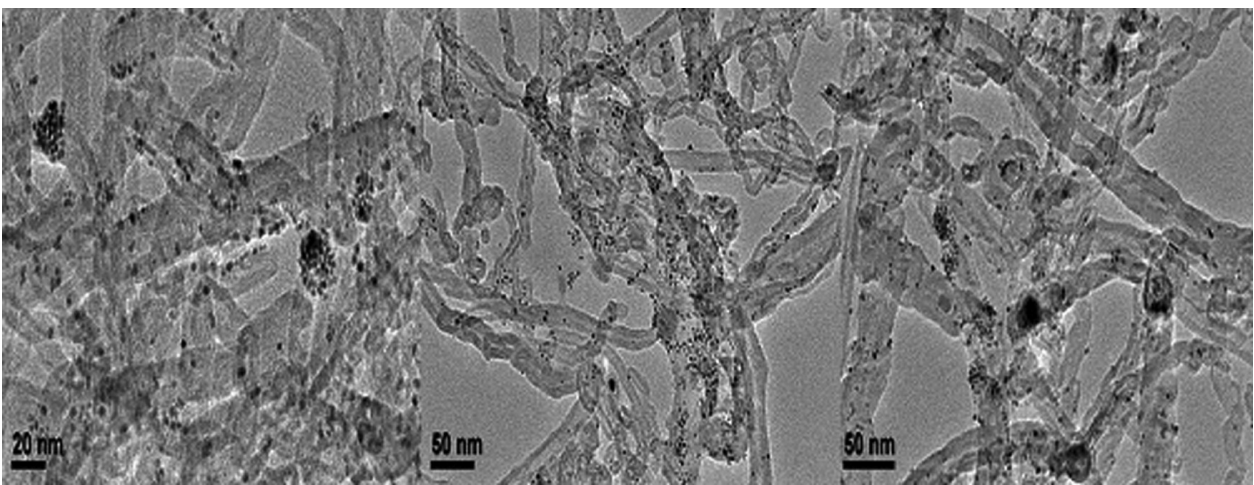

Figure 15. TEM images of the recycled Pt/MWCNT catalyst.

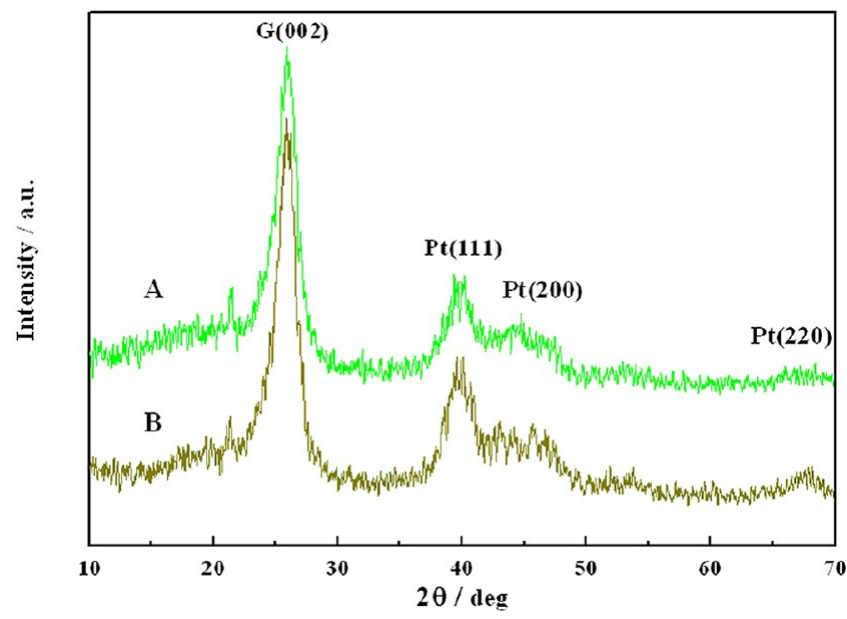

Figure 16. XRD patterns of the Pt/MWCNT catalyst (A: fresh; B: after recycling six times).

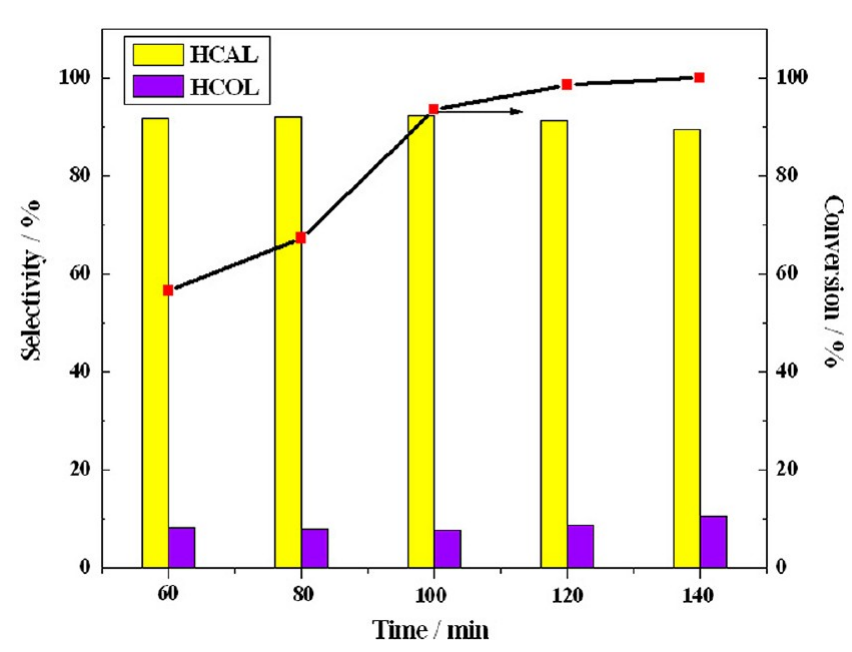

Figure 17. Effect of reaction time on the catalytic performance of the $\mathrm{Pd} /$ MWCNT catalyst (reaction conditions: $0.06 \mathrm{~g}$ of catalyst, $2 \mathrm{~mL}$ of $\mathrm{CAL}, 6 \mathrm{~mL}$ of TFEOH, $4 \mathrm{MPa} \mathrm{H}_{2}, 14.8 \mathrm{MPa} \mathrm{CO}_{2}, 6{ }^{\circ} \mathrm{C}$ ).

reactants are at a maximum, which was shown to improve the hydrogenation reaction efficiency and to increase the CAL conversion to $80 \%$. As the $\mathrm{CO}_{2}$ pressure further increased, the conversion amount and the selectivity for $\mathrm{COL}$ decreased, which indicated that excess $\mathrm{CO}_{2}$ reduced the density of $\mathrm{H}_{2}$.

Figures 9 and 10 show that with an increase of $\mathrm{CO}_{2}$ pressure in the $\mathrm{CAL}$ and $\mathrm{CO}_{2}$ mixture, the $\nu(\mathrm{C}=\mathrm{O})$ and the $\nu(\mathrm{C}=\mathrm{C})$

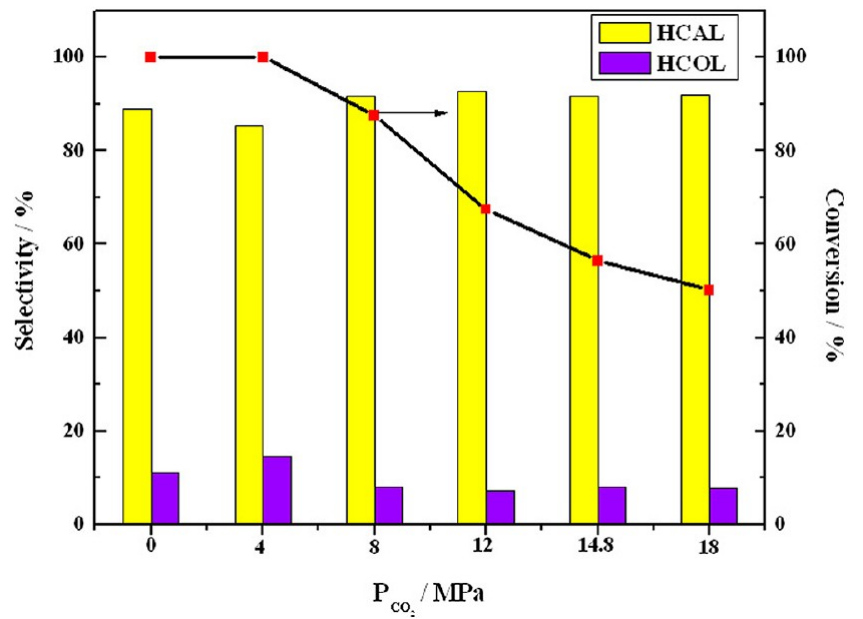

Figure 18. Effect of $\mathrm{CO}_{2}$ pressure on the catalytic performance of the Pd/MWCNT catalyst (reaction conditions: $0.06 \mathrm{~g}$ of catalyst, $2 \mathrm{~mL}$ of $\mathrm{CAL}, 6 \mathrm{~mL}$ of TFEOH, $4 \mathrm{MPa} \mathrm{H}_{2}, 60^{\circ} \mathrm{C}, 1 \mathrm{~h}$ ).

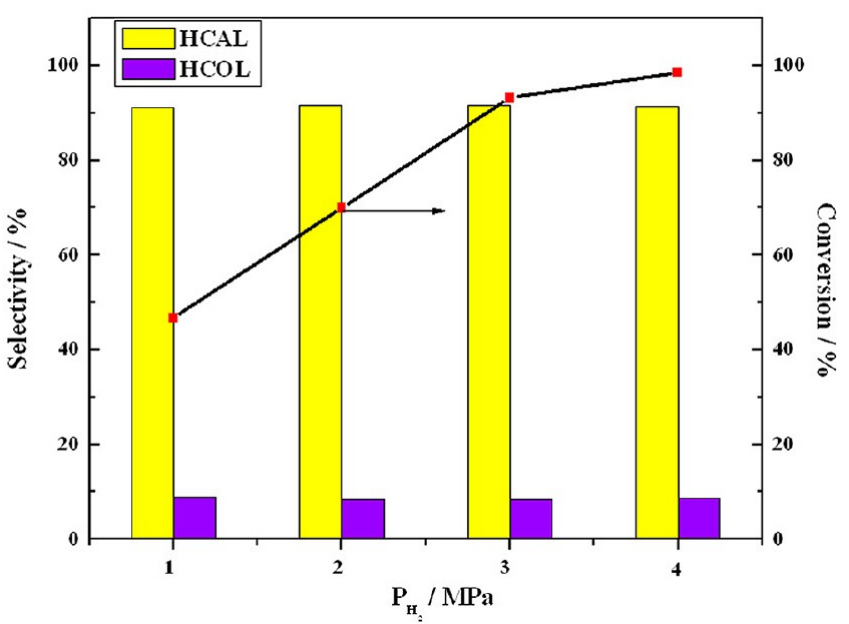

Figure 19. Effect of $\mathrm{H}_{2}$ pressure on the catalytic performance of the $\mathrm{Pd} / \mathrm{MWCNT}$ catalyst (reaction conditions: $0.06 \mathrm{~g}$ of catalyst, $2 \mathrm{~mL}$ of $\mathrm{CAL}, 6 \mathrm{~mL}$ of TFEOH, $14.8 \mathrm{MPa} \mathrm{CO}_{2}, 60^{\circ} \mathrm{C}, 2 \mathrm{~h}$ ).

frequencies of CAL both blue-shifted. The results showed that at $\mathrm{CO}_{2}$ pressures up to $27.5 \mathrm{MPa}$ (where the system transitions into a single phase $)$, the $\nu(\mathrm{C}=\mathrm{O})$ absorption peak shifted from 1669 to $1685 \mathrm{~cm}^{-1}\left(16 \mathrm{~cm}^{-1}\right.$ blue shift $)$, but the $\nu(\mathrm{C}=\mathrm{C})$ absorption peak only shifted from 1622 to $1627 \mathrm{~cm}^{-1}\left(5 \mathrm{~cm}^{-1}\right.$ blue shift), indicating that the interactions between $\mathrm{CO}_{2}$ 


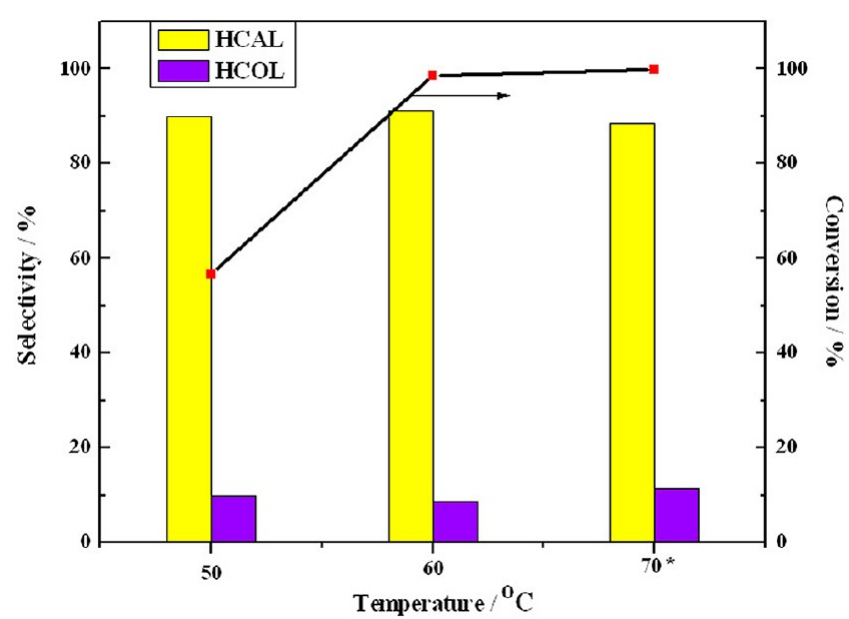

Figure 20. Effect of temperature on the catalytic performance of the $\mathrm{Pd} / \mathrm{MWCNT}$ catalyst (reaction condition: $0.06 \mathrm{~g}$ of catalyst, $2 \mathrm{~mL}$ of CAL, $6 \mathrm{~mL}$ of TFEOH, $\left.4 \mathrm{MPa} \mathrm{H}_{2}, 14.8 \mathrm{MPa} \mathrm{CO}_{2}, 2 \mathrm{~h}(* 1 \mathrm{~h})\right)$.

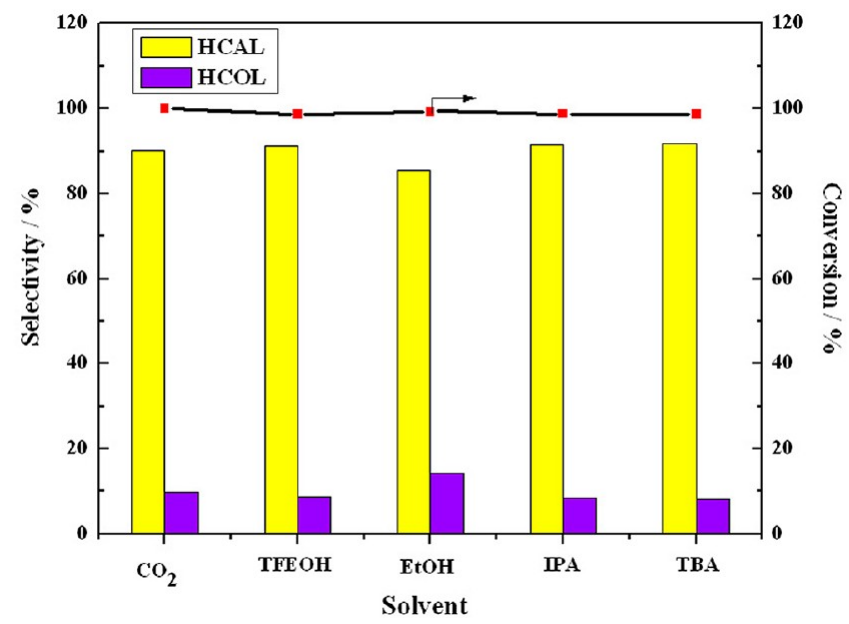

Figure 21. Effect of different cosolvents on the catalytic performance of the Pd/MWCNT catalyst (reaction condition: $0.06 \mathrm{~g}$ of catalyst, 2 $\mathrm{mL}$ of CAL, $6 \mathrm{~mL}$ of solvent, $4 \mathrm{MPa} \mathrm{H}_{2}, 14.8 \mathrm{MPa} \mathrm{CO}_{2}, 2 \mathrm{~h}, 60^{\circ} \mathrm{C}$ ).

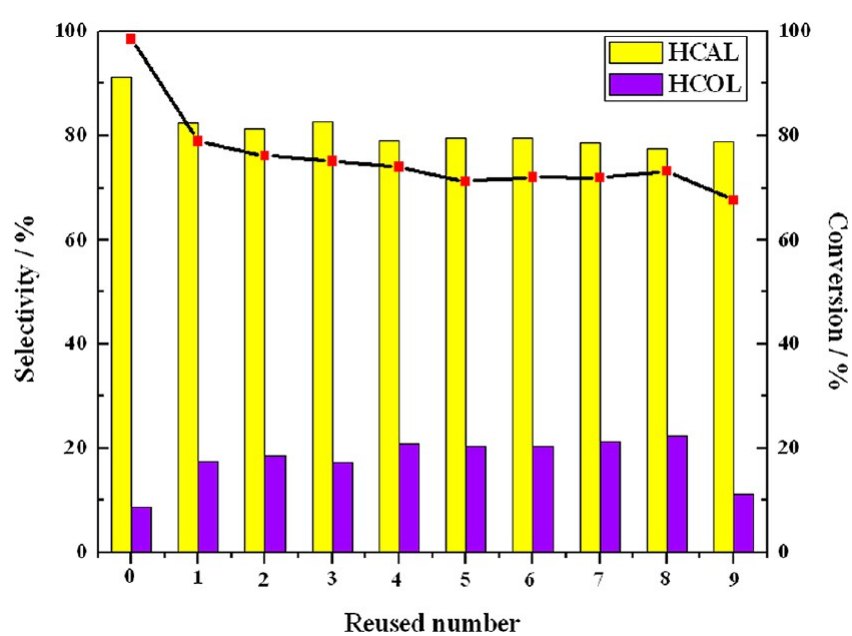

Figure 22. Stability of the Pd/MWCNT catalyst (reaction conditions: $0.06 \mathrm{~g}$ of catalyst, $2 \mathrm{~mL}$ of CAL, $6 \mathrm{~mL}$ of TFEOH, $4 \mathrm{MPa} \mathrm{H}_{2}, 14.8$ $\left.\mathrm{MPa} \mathrm{CO}_{2}, 60^{\circ} \mathrm{C}, 9 \mathrm{~h}\right)$. molecules and the $\mathrm{C}=\mathrm{O}$ bonds of $\mathrm{CAL}$ were stronger. Therefore, $\mathrm{CO}_{2}$ activates the $\mathrm{C}=\mathrm{O}$ bond of $\mathrm{CAL}$ to improve the hydrogenation reaction. ${ }^{27}$ With an increase of $\mathrm{CO}_{2}$ pressure, the selective hydrogenation of CAL selectively forms COL. When the $\mathrm{CO}_{2}$ pressure reaches $27.5 \mathrm{MPa}$, CAL and $\mathrm{CO}_{2}$ combine and become a single phase. At higher pressures, the frequencies remained constant, indicating that the interactions between $\mathrm{CO}_{2}$ molecules and the $\mathrm{C}=\mathrm{O}$ and $\mathrm{C}=\mathrm{C}$ bonds of CAL did not change. Therefore, the frequencies did not change with an increase of $\mathrm{CO}_{2}$ pressure as observed in our previous study. ${ }^{23}$

Effect of $\mathrm{H}_{2}$ Pressure. Figure 11 shows the effect of $\mathrm{H}_{2}$ pressure on the catalytic performance. The CAL conversion percentage increased from 14 to $78 \%$ as $\mathrm{H}_{2}$ pressure increased, and the selectivity for COL also increased from 92 to $98 \%$. When $\mathrm{H}_{2}$ pressure increased from 4.0 to $4.5 \mathrm{MPa}$, the conversion percentage and selectivity for COL reached a maximum and then remained constant. The collision rate of $\mathrm{H}_{2}$ with CAL and the catalyst increased with $\mathrm{H}_{2}$ pressure. This improved the conversion percentage and reaction rate.

Effect of Temperature. Figure 12 shows the changes in selectivity and the conversion percentage with increasing temperature over the $\mathrm{Pt} / \mathrm{MWCNT}$ catalyst. Increasing the temperature from 50 to $70{ }^{\circ} \mathrm{C}$ caused the $\mathrm{CAL}$ conversion percentage and the selectivity for COL to change from 36 to $99 \%$ and from 86 to $97 \%$, respectively. The experimental results indicate that increasing the reaction temperature improves the CAL hydrogenation reaction rate.

Effect of Cosolvents. Figure 13 shows the effect of different cosolvents on the catalytic performance of the Pt/MWCNT catalyst. For the CAL hydrogenation reaction in CXL, using pure supercritical carbon dioxide as a solvent may work well for mass transfer, but $\mathrm{scCO}_{2}$ may not activate the $\mathrm{C}=\mathrm{O}$ bonds. Therefore, a certain amount of cosolvent that can improve the CAL conversion and the selectivity for COL should be added. Under the same reaction conditions, a more polar cosolvent among the EtOH, isopropanol (IPA), and tert-butanol (TBA), the EtOH gave a higher selectivity for COL. With TFEOH as a cosolvent, the reaction showed a slightly lower conversion percentage as well as a high selectivity for COL, which may be due to its stronger acidity compared to the other solvents.

Stability of the Pt/MWCNT Catalyst. Figure 14 shows the stability of the Pt/MWCNT catalyst. The conversion and the selectivity for COL gradually declined as the catalyst was reused. The TEM images (Figure 15) show that the Pt particles on the surface of the MWCNTs migrated and gathered together, reducing the catalyst active site and decreasing the catalytic activity. The XRD patterns (Figure 16) show that the characteristic Pt diffraction peak (111) was sharper after the Pt/ MWCNT catalyst was recycled six times (B) than it was for the fresh $\mathrm{Pt} / \mathrm{MWCNT}$ catalyst (A), indicating that the Pt particle size increased, which was observed in the TEM images.

Selective Hydrogenation of CAL over 5.0 wt.\% Pd/ MWCNT Catalysts. Effect of Reaction Time. The Pt/ MWCNT catalyst exhibits a highly selective hydrogenation toward $\mathrm{C}=\mathrm{O}$ bonds (COL), while the Pd/MWCNT catalyst provides a highly selective hydrogenation toward $\mathrm{C}=\mathrm{C}$ bonds (HCAL). Figure 17 shows the effects of reaction time on the product distribution at a fixed temperature of $60{ }^{\circ} \mathrm{C}$ over the 5.0 wt.\% Pd/MWCNT catalyst. The CAL conversion percentage gradually increased with reaction time. The conversion reached $100 \%$ at a reaction time of $140 \mathrm{~min}$. There were only two products, HCAL and HCOL, and the 


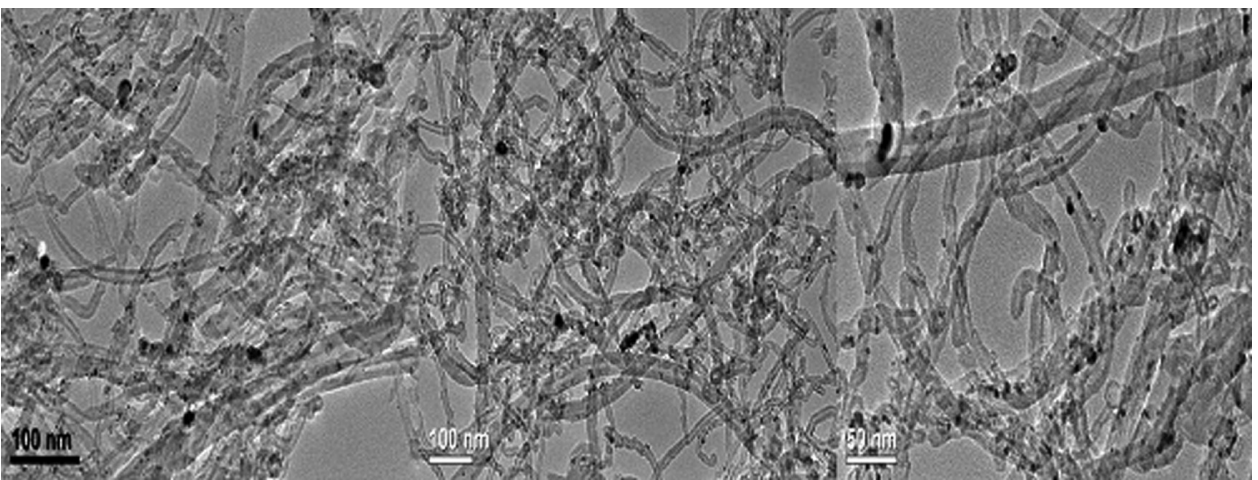

Figure 23. TEM images of the Pd/MWCNT catalyst after recycling nine times.

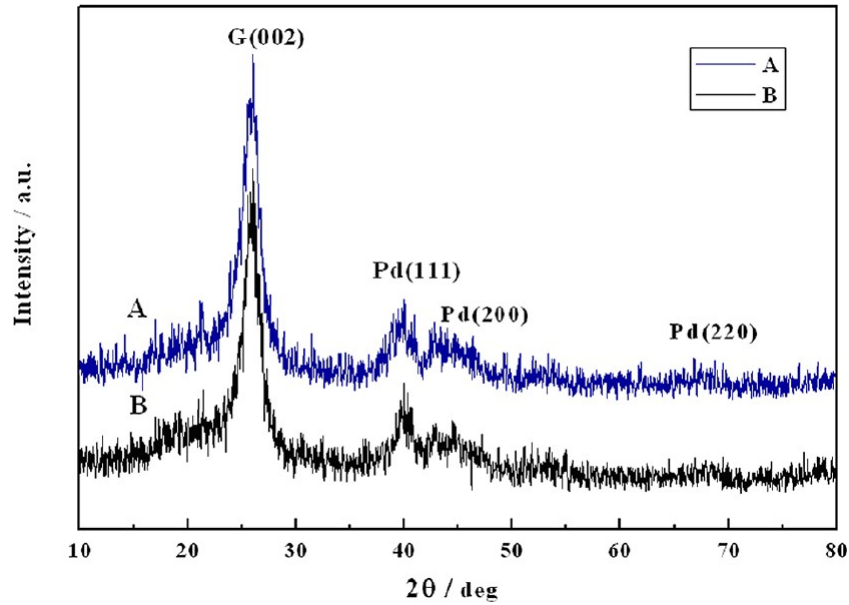

Figure 24. XRD patterns of the Pd/MWCNT catalyst (A: fresh; B: after recycling nine times).

selectivity for HCAL remained at approximately $90 \%$. Because the selective hydrogenation of $\mathrm{C}=\mathrm{C}$ bonds is thermodynamically more favorable than that of $\mathrm{C}=\mathrm{O}$ bonds, the $\mathrm{C}=\mathrm{C}$ bond hydrogenation is much easier to obtain under the same reaction conditions.

Effect of $\mathrm{CO}_{2}$ Pressure. Figure 18 shows the effect of $\mathrm{CO}_{2}$ pressure on the product distribution over a $\mathrm{CO}_{2}$ pressure range of 0 to $18 \mathrm{MPa}$ for the CAL selective hydrogenation over the $\mathrm{Pd} / \mathrm{MWCNT}$ catalyst. The changes of $\mathrm{CO}_{2}$ pressure had a great influence on the CAL conversion percentage, which can be described as follows: (1) When there was no $\mathrm{CO}_{2}$ in the reaction system, the selectivity for HCAL approached 90\%, and the conversion percentage was $100 \%$. After introducing $\mathrm{CO}_{2}$ below the critical pressure $(7.38 \mathrm{MPa})$, the selectivity for HCAL slightly declined, but the CAL conversion percentage still remained at $100 \%$, which showed that the activity of the $\mathrm{Pd} / \mathrm{MWCNT}$ catalyst was very high and that gaseous $\mathrm{CO}_{2}$ did not affect the hydrogenation reaction rate. (2) When the $\mathrm{CO}_{2}$ pressure reached the critical value, the CAL conversion percentage greatly decreased as $\mathrm{CO}_{2}$ pressure increased, but the selectivities for HCAL and HCOL products remained unchanged. This may result from the decrease in reactant (CAL and $\mathrm{H}_{2}$ ) concentration, reducing the hydrogenation reaction rate. Supercritical $\mathrm{CO}_{2}$ has also been suggested to suppress the $\mathrm{C}=\mathrm{C}$ bond hydrogenation rate.

Effect of $\mathrm{H}_{2}$ Pressure. Figure 19 demonstrates the significant effect of $\mathrm{H}_{2}$ pressure on the CAL conversion percentage at a constant temperature of $60{ }^{\circ} \mathrm{C}$ and a $\mathrm{CO}_{2}$ pressure of 14.8
MPa. With an increase of $\mathrm{H}_{2}$ pressure from 1 to $4 \mathrm{MPa}$, the CAL conversion percentage changed from 47 to $99 \%$. Increasing the concentration of $\mathrm{H}_{2}$ could saturate the catalyst with hydrogen, causing an increase in the transfer of hydrogen to CAL, thus improving the CAL conversion percentage.

Effect of Temperature. Figure 20 shows that increasing the reaction temperature improves the CAL conversion percentage. At $50{ }^{\circ} \mathrm{C}$ for $2 \mathrm{~h}$, the CAL conversion percentage was $57 \%$; at $60{ }^{\circ} \mathrm{C}$ for $2 \mathrm{~h}$, the CAL conversion percentage was $97 \%$; and at $70{ }^{\circ} \mathrm{C}$ for only $1 \mathrm{~h}$, the CAL conversion percentage approached $100 \%$. This indicates that a higher reaction temperature can effectively activate the $\mathrm{C}=\mathrm{C}$ bonds.

Effect of Cosolvents. Figure 21 shows the effect of different cosolvents on the catalytic performance of the Pd/MWCNT catalyst. Under the same reaction conditions, the effect of cosolvents was not obvious. However, when $\mathrm{EtOH}$ was used as a cosolvent, the selectivity for HCAL decreased, and the selectivity for HCOL increased. This shows that in all tested cosolvents, higher polarity correlates with a higher selectivity for hydrogenation of the $\mathrm{C}=\mathrm{O}$ bond.

Stability of the Pd/MWCNT Catalyst. Figure 22 shows the stability of the Pd/MWCNT catalyst. As the catalyst was reused, the catalytic activity gradually decreased, and after the catalyst was reused nine times, the CAL conversion percentage decreased to $70 \%$, and the main product selectivity for HCAL also dropped to $80 \%$. Figures 23 and 24 show the TEM images and the XRD patterns of the recycled Pd/MWCNT catalyst, respectively. The results indicate that $\mathrm{Pd}$ particles accumulated together and reduced the effective active site size, which was the main reason for the decreasing catalyst performance.

\section{CONCLUSIONS}

In this paper, we have investigated the effects of reaction time, $\mathrm{CO}_{2}$ pressure, $\mathrm{H}_{2}$ pressure, reaction temperature, and cosolvent on the product distribution for the selective hydrogenation of CAL over Pt and Pd nanoparticles supported on MWCNTs in a $\mathrm{CO}_{2}$-expanded alcoholic medium. Under the studied reaction conditions, the Pt/MWCNT catalyst demonstrated a remarkably high selectivity of more than $97 \%$ for the unsaturated alcohol (COL). Conversely, the Pd/MWCNT catalyst demonstrated a remarkably high selectivity of more than $91 \%$ for the saturated aldehyde (HCAL). The $\mathrm{CO}_{2}$-expanded CAL medium promotes the hydrogenation of the $\mathrm{C}=\mathrm{O}$ bonds but restrains that of the $\mathrm{C}=\mathrm{C}$ bonds. A certain amount of polar cosolvent activates $\mathrm{C}=\mathrm{O}$ bonds and improves the selectivity for unsaturated alcohol. The material is stable after being used six times for the Pt/MWCNT catalyst and nine times for the 
$\mathrm{Pd} / \mathrm{MWCNT}$ catalyst. The deactivation of the catalyst is mainly due to particle aggregation during the reaction process.

\section{AUTHOR INFORMATION}

\section{Corresponding Author}

*Tel. and Fax: 86-29-81530802. E-mail: ztliu@snnu.edu.cn.

\section{Notes}

The authors declare no competing financial interest.

\section{ACKNOWLEDGMENTS}

We gratefully acknowledge the financial support of the National Natural Science Foundation of China (20976102, 21176151) and the Changjiang Scholars and Innovative Research Team in University (IRT 1070).

\section{REFERENCES}

(1) Rase, H. F. Handbook of Commercial Catalysts-Heterogeneous Catalysts; CRC Press LLC: Boca Raton, FL, 2000; p 174.

(2) Gallezot, P.; Richard, D. Selective Hydrogenation of $\alpha, \beta$ Unsaturated Aldehydes. Catal. Rev. Sci. Eng. 1998, 40, 81-126.

(3) Chen, X.; Li, H.; Dai, W.; Wang, J.; Ran, Y.; Qiao, M. Selective Hydrogenation of Cinnamaldehyde to Cinnamyl Alcohol over the Co$\mathrm{La}-\mathrm{B} / \mathrm{SiO}_{2}$ Amorphous Catalyst and Promoting effect of La-dopant. Appl. Catal., A 2003, 253 (2), 359-369.

(4) Bauer, K.; Garbe, D. Common Fragrances and Flavor Materials: Preparation, Properties, and Uses; VCH: Weinheim, 1985.

(5) Cordier, G.; Colleuille, Y.; Fouilloux, P. In Imelik, B. et al., Eds. Catalyse par les Métaux; Editions du CNRS: Paris, 1984; p 349.

(6) Claus, P. Selective Hydrogenation of $\alpha, \beta$-Unsaturated Aldehydes and other $\mathrm{C}=\mathrm{O}$ and $\mathrm{C}=\mathrm{C}$ bonds Containing Compounds. Top. Catal. 1998, 5 (1-4), 51-62.

(7) Sokol'skii, D. V.; Anisimova, N. V.; Zharmagambetova, A. K.; Ualikhanova, A. Effect of Hydrogen Pressure on the Selectivity of 2Butene-1-al Hydrogenation. Catal. Lett. 1981, 17, 419-421.

(8) Qiu, J.; Hong, Z.; Xiu, N.; Han, H.; Liang, H.; Li, C. Selective Hydrogenation of Cinnamaldehyde over Carbon Nanotube Supported Pd-Ru Catalyst. Catal. Lett. 2006, 88, 269-275.

(9) Singh, U. K.; Vannice, M. A. Liquid-Phase Citral Hydrogenation over $\mathrm{SiO}_{2}$-Supported Group VIII Metals. J. Catal. 2001, 199 (1), 7384.

(10) Aramendia, M. A.; Borau, V.; Jimenez, C.; Marinas, J. M.; Porras, A.; Urbano, F. J. Selective Liquid-Phase Hydrogenation of Citral over Supported Palladium. J. Catal. 1997, 172 (1), 46-54.

(11) Aumo, J.; Lilja, J.; Maki-Arvela, P.; Salmi, T.; Sundell, M.; Vainio, H.; Murzin, D. Y. Hydrogenation of Citral over a Polymer Fibre Catalyst. Catal. Lett. 2002, 84 (3-4), 219-224.

(12) Iijima, S. Helical Microtubes of Graphite Carbon. Nature 1991, $354,56-58$

(13) Nhut, J. M.; Pesant, L.; Tessonnier, J. P.; Winé, G.; Guille, J.; Pham-Huu, C.; Ledoux, M. J. Mesoporous Carbon Nanotubes for use as Support in Catalysis and as Nanosized Reactors for OneDimensional Inorganic Material Synthesis. Appl. Catal., A 2003, 254 (2), 345-363.

(14) Lordi, V.; Yao, N. Molecular Mechanics of Binding in CarbonNanotube-Polymer Composites. J. Mater. Res. 2000, 15, 2770-2779.

(15) Samant, P. V.; Pereira, M. F. R.; Figueiredo, J. L. Mesoporous Carbon Supported Pt and Pt-Sn Catalysts for Hydrogenation of Cinnamaldehyde. Catal. Today 2005, 102-103, 183-188.

(16) Coq, B.; Brotons, V.; Planeix, J. M.; Charles de Menorval, L.; Dutartre, R. Platinum Supported on [60]Fullerene-Grafted Silica as a New Potential Catalyst for Hydrogenation. J. Catal. 1998, 176 (2), $358-364$.

(17) Planeix, J. M.; Coustel, N.; Coq, B.; Brotons, V.; Kumlar, P. S.; Dutartre, R.; Geneste, P.; Bernieer, P.; Ajayan, P. M. Application of Carbon Nanotubes as Supports in Heterogeneous Catalysis. J. Am. Chem. Soc. 1994, 116 (17), 7935-7936.
(18) Liu, Z.-T.; Wang, C. X.; Liu, Z.-W.; Lu, J. Selective Hydrogenation of Cinnamaldehyde over Pt-supported Multi-walled Carbon Nanotubes: Insights into the Tube-size Effects[J]. Appl. Catal., A 2008, 344 (1-2), 114-123.

(19) Jessop, P. G.; Subramaniam, B. Gas-Expanded Liquids. Chem. Rev. 2007, 107 (6), 2666-2694.

(20) Jessop, P. G.; Ikariya, T.; Noyori, R. Homogeneous CatalyticHydrogenation of Supercritical Carbon-Dioxide. Nature (London) 1994, 368 (6468), 231-233.

(21) Jessop, P. G.; Hsiano, Y.; Ikariya, T.; Noyori, R. Homogeneous Catalysis in Supercritical Fluids: Hydrogenation of Supercritical Carbon Dioxide to Formic Acid, Alkyl Formates, and Formamides. J. Am. Chem. Soc. 1996, 118 (2), 344-355.

(22) Bank, M. J.; Feng, S.; Gross, M. F.; Tumas, W. Asymmetric Catalytic Hydrogenation Reactions in Supercritical Carbon Dioxide. J. Am. Chem. Soc. 1995, 117 (31), 8277-8278.

(23) Liu, Z. T.; Chen, J. G.; Liu, Z. W.; Lu, J. New Process for Synthesizing Fluorinated Polymers in Supercritical Carbon Dioxide. Macromolecules 2008, 41, 6987-6992.

(24) Chen, J. G.; Liu, X.; Liu, Z. W.; Hu, D. D.; Zhang, C. J.; Xue, D.; Xiao, J. L.; Liu, Z. T. Intermolecular-Interaction-Dominated Solvation Behaviors of Liquid Monomers and Polymers in Gaseous and Supercritical Carbon Dioxide. Macromolecules 2012, 45, 4907-4919.

(25) Xing, Y. C.; Li, L.; Chusuei, C. C.; Hull, R. V. Sonochemical Oxidation of Multiwalled Carbon Nanotubes. Langmuir 2005, 21, 4185-4190.

(26) Meng, L. J.; Fu, C. L.; Lu, Q. H. Advanced Technology for Functionalization of Carbon Nanotubes. Prog. Nat. Sci. 2009, 19, 801810.

(27) Zhao, F. Y.; Fujita, S.-I.; Akihara, S.; Arai, M. Hydrogenation of Benzaldehyde and Cinnamaldehyde in compressed $\mathrm{CO}_{2}$ Medium with a Pt/C Catalyst: a study on Molecular Interactions and Pressure Effects. J. Phys. Chem. A 2005, 109 (19), 4419-4424. 